\title{
Florestas em territórios de fronteira: Sul do Brasil e Misiones na Argentina $^{1}$
}

\section{Forests in border territories: southern Brazil and Misiones in Argentina}

Eunice Sueli Nodari*

\begin{abstract}
Resumo
$\mathrm{O}$ artigo analisa as descrições feitas por dois viajantes argentinos sobre a região de Misiones no final do século XIX. Parte da Província de Misiones na Argentina está inserida no Bioma Mata Atlântica, deixando evidente que a natureza independe de limites impostos pelos seres humanos. Ênfase será dada à descrição da natureza e o estabelecimento de imigrantes.

Palavras-chaves: História Ambiental; paisagens; fronteiras, Bioma Mata Atlântica
\end{abstract}

\begin{abstract}
The paper analyzes reports written by two Argentinian travelers, at the end of the 19th century, about the region of Misiones. Part of the Province of Misiones in Argentina is a continuity of the Brazilian Atlantic Biome, so showing that nature is independent of limits imposed by human beings. Emphasis will be given on the description of nature and settlement of migrants.
\end{abstract}

Keywords: Environmental History; landscapes; frontiers; Atlantic Forest Biome

A História Ambiental permite ousar e ultrapassar fronteiras que, afinal, são fluídas, e construídas cultural e politicamente pelos humanos. Os

\footnotetext{
* Doutora em História pela PUC/RS. Professora do Departamento de História, do Programa de Pós-Graduação em História e do Programa Interdisciplinar em Ciências Humanas da Universidade Federal de Santa Catarina. Professora visitante na Universidade de Stanford, EUA (agosto de 2015 a fevereiro de 2016) E-mail: Eunice.nodari@ufsc.br

${ }^{1}$ Este artigo faz parte do projeto "As delimitações espaciais na pesquisa em História Ambiental”, financiado pelo CNPq, Chamada Universal 14/2012; e do projeto "Domesticando paisagens na América Meridional" - Bolsa Pós-Doutorado do CNPq.
} 
temas da História Ambiental, frequentemente, desafiam uma delimitação espacial mais tradicional, baseada nas fronteiras nacionais fazendo com que o historiador ambiental supere também as fronteiras políticas. ${ }^{2}$

Um dos exemplos típicos é o bioma Mata Atlântica, onde a flora e a fauna não respeitaram as fronteiras nacionais delimitadas por decisões políticas. Desta forma, a natureza, mesmo com os limites traçados é ininterrupta entre o Sul do Brasil e Misiones na Argentina. No presente artigo faremos uma discussão sobre as impressões escritas, relacionadas ao meio ambiente, por dois viajantes argentinos no final do século XIX para a região de Misiones e partes do Sul do Brasil.

Os limites a partir de atributos naturais são importantes para que possa entender a natureza como algo ativo e dinâmico e a sua influência na sociedade e cultura e, muitas vezes, acabam sendo responsáveis pelas escolhas humanas. A História Ambiental rejeita a ideia de que as ações humanas estão isentas de restrições naturais e, de outra forma, de que as sociedades humanas não sofrem influência de condicionantes naturais. ${ }^{3}$

$\mathrm{Na}$ mesma perspectiva de Worster, a pesquisadora Harriet Ritvo ${ }^{4} \mathrm{su}^{-}$ gere que as pesquisas deveriam transcender as fronteiras nacionais, usando o método comparativo ou fazendo uso da interdisciplinaridade que oferece categorias alternativas para analisar o mundo. A autora lamenta que grande parte dos historiadores ambientais adotam os limites construídos pelos humanos tais como a fronteira nacional, a língua e a cultura. Nos nossos estudos poderíamos afirmar que a fronteira do Brasil com a Argentina, com suas similaridades ambientais é somente uma linha no mapa, ou separada por um acidente geográfico. Todavia, não podemos ignorar as questões socioculturais, que podem ser bem distintas, sem dúvida, mas não impedindo que se escreva uma história através de comparações entre as semelhanças e diferenças encontradas. Os estudos comparativos são importantes, pois permitem que sejam analisados aspectos relacionados com as mudanças ambientais, por exemplo, que têm provocado, muitas vezes, respostas similares em espaços bem distantes uns dos outros. ${ }^{5}$

\footnotetext{
${ }^{2}$ WORSTER, Donald. Para fazer História Ambiental. Estudos Históricos, Rio de Janeiro, v. 4, n. 8, 1991 , p. 199. ${ }^{3}$ Ibidem.

${ }^{4}$ RITVO, Harriet. Broader Horizons? In: COULTER, Kimberly, MAUCH, Christof (Org.). The future of Environmental History: Needs and Opportunities. Munich: RCC Perspectives, Ludwig-MaximiliansUniversitat, 2011/3.

${ }^{5}$ Ibidem, p. 23.
} 
De acordo com David Blackbourn, na medida em que os historiadores ambientais examinam o habitat, questionam uma paisagem, ou assinalam o movimento de espécies invasoras, mostram-se fundamentais em devolver a dimensão espacial à história, ocorrida nos últimos anos. ${ }^{6}$ Ressalta ainda, 0 referido autor, que a História Ambiental deveria ser escrita transversalmente nas escalas temporais, da deep history à história de uma crise, como um incêndio ou uma enchente, que abrem uma janela para questões mais amplas. ${ }^{7}$

Concordamos com Blackbourn, que existem ainda outros desafios, tanto práticos quanto conceituais, como por exemplo, onde se encontra a fronteira entre história e história natural? Em que medida podemos transformar, por exemplo, um rio ou uma espécie não-humana como sujeitos e não somente como objetos da nossa pesquisa, e continuar escrevendo história?

A História Ambiental, pela sua própria natureza, desafia a historiografia nacional, tanto em nível sub quanto supranacional - o local e o global, mesmo que as historiografias sejam definidas nacionalmente. Frank Uekoetter $^{8}$ discute a globalização da História Ambiental e seu argumento é que além de muitos insights específicos, ela oferece uma grande oportunidade: a de tornar a história global mais simples. $\mathrm{O}$ autor afirma que todo o historiador global está lutando com a complexidade do mundo: culturas, sistemas políticos e economias que diferem tanto em níveis nacionais, regionais e locais. Todavia, quando chega a interação do homem com a biosfera, as leis da natureza têm um bom conjunto de similaridades ao redor do mundo. Como exemplo, cita entre outros, a questão dos fazendeiros que se dedicam à monocultura, sendo que em qualquer parte do mundo as pestes e doenças se multiplicam. As reações, sem dúvida, tem inúmeras diferenças, “mas os desafios básicos são notavelmente similares", e isto pode se tornar uma grande vantagem num campo que está batalhando com a diversidade do globo. ${ }^{9}$

Uekoetter, deixa evidente que este tipo de história terá custos, pois exige que nos afastemos de uma síntese global ampla e que nos dediquemos aos problemas e questões que são similares o suficiente ao redor do mundo. $\mathrm{Na}$ verdade, esta proposta do autor seria mais transnacional do que global,

\footnotetext{
${ }^{6}$ BLACKBOURN, David. Environmental History and Other Histories. In: COULTER, MAUCH, (Org.) op, cit.. p. 19. ${ }^{7}$ Ibidem, p. 20.

${ }^{8}$ UEKOETTER, Frank. Globalizing Environmental History - Again. In: COULTER, MAUCH (Org.), op. cit., p. $24-25$.

${ }^{9}$ Ibidem, p. 25.
} 
na qual a chave de escolha seria onde desafios ecológicos comuns podem ser identificados, podendo juntar regiões de diferentes cantos do mundo em vez do planeta todo. $O$ autor defende a ideia de que o pesquisador deve se afastar de uma síntese global, e em seu lugar trabalhar com questões e problemas que apresentem similaridades. Como exemplo podem ser analisados os desmatamentos em florestas tropicais que estão sendo substituídas em diferentes partes do mundo por commodities agrícolas.

Parte da região da fronteira entre o Brasil e a Argentina pode ser considerada nos termos acima mencionados e, além disso, ser identificada com o que Benedict Anderson denomina de comunidades imaginadas ${ }^{10}$, no que se refere às questões relacionadas ao meio ambiente, pois pode-se inferir que a natureza, assim como os aspectos culturais dos moradores da região, ajudou ao sentimento de pertencimento. As pessoas, ao se estabelecerem na região, procuravam algo que os identificasse com o seu antigo lar, no caso dos imigrantes que se estabeleceram em ambos os lados. Por delimitação política temos duas regiões bastante idênticas no que se refere à flora e à fauna, em países distintos.

No presente texto iremos nos ater na análise dos textos de dois escritores-viajantes que percorreram a região de Misiones no final do século XIX e os seus relatos, especialmente aqueles voltados à descrição da natureza. A forma como estes dois autores descrevem a natureza, pode ser considerada dentro do padrão da época, ou seja, era no mesmo formato com os europeus ao visitarem diferentes regiões as descreviam, com o seu olhar de superioridade. Todavia, os olhares dos viajantes argentinos demonstram uma grande preocupação em atender à "necessidade" que o governo argentino tinha em "civilizar" as regiões de fronteira. Como bem analisa Bruno Aranha em sua dissertação de mestrado,

Eram os civilizados de Buenos Aires que partiram em direção à barbárie desconhecida de Misiones. Levar a civilização e o desenvolvimento para um lugar ainda considerado bárbaro, era uma tarefa que julgavam realizar em nome da pátria. ${ }^{11}$

Era importante que nesta política de expansão das fronteiras, que era uma das metas do governo da Argentina, contasse com o apoio logístico de

\footnotetext{
${ }^{10}$ ANDERSON, Benedict. Comunidades Imaginadas. São Paulo: Cia das Letras, 2008.

${ }^{11}$ ARANHA, Bruno Pereira de Lima. De Buenos Aires a Misiones: civilização e barbárie nos relatos de viagens realizadas à terra do mate (1882-1898). Dissertação (Mestrado) - Programa de Pós-Graduação em Integração da América Latina, Universidade de São Paulo, São Paulo, 2014.
} 
intelectuais, pois além realizarem o trabalho de campo, davam também credibilidade acadêmica ao projeto de modelo de nação que estava em marcha. Atualmente, a província de Misiones tem uma superfície de 30.719 $\mathrm{km}^{2}$, com uma topografia ondulada com altura que vai de $120 \mathrm{~m}$ a mais de $800 \mathrm{~m}$ do nível do mar. Apresenta cinco zonas morfológicas distintas: a peneplanície meridional ou de Apóstoles, ribeira ondulada do Paraná, colinas do Uruguay, as costas serranas centrais e a altiplanície de Bernardo de Irigoyen. (Mapa1)

Mapa 1 - Província de Misiones - Argentina

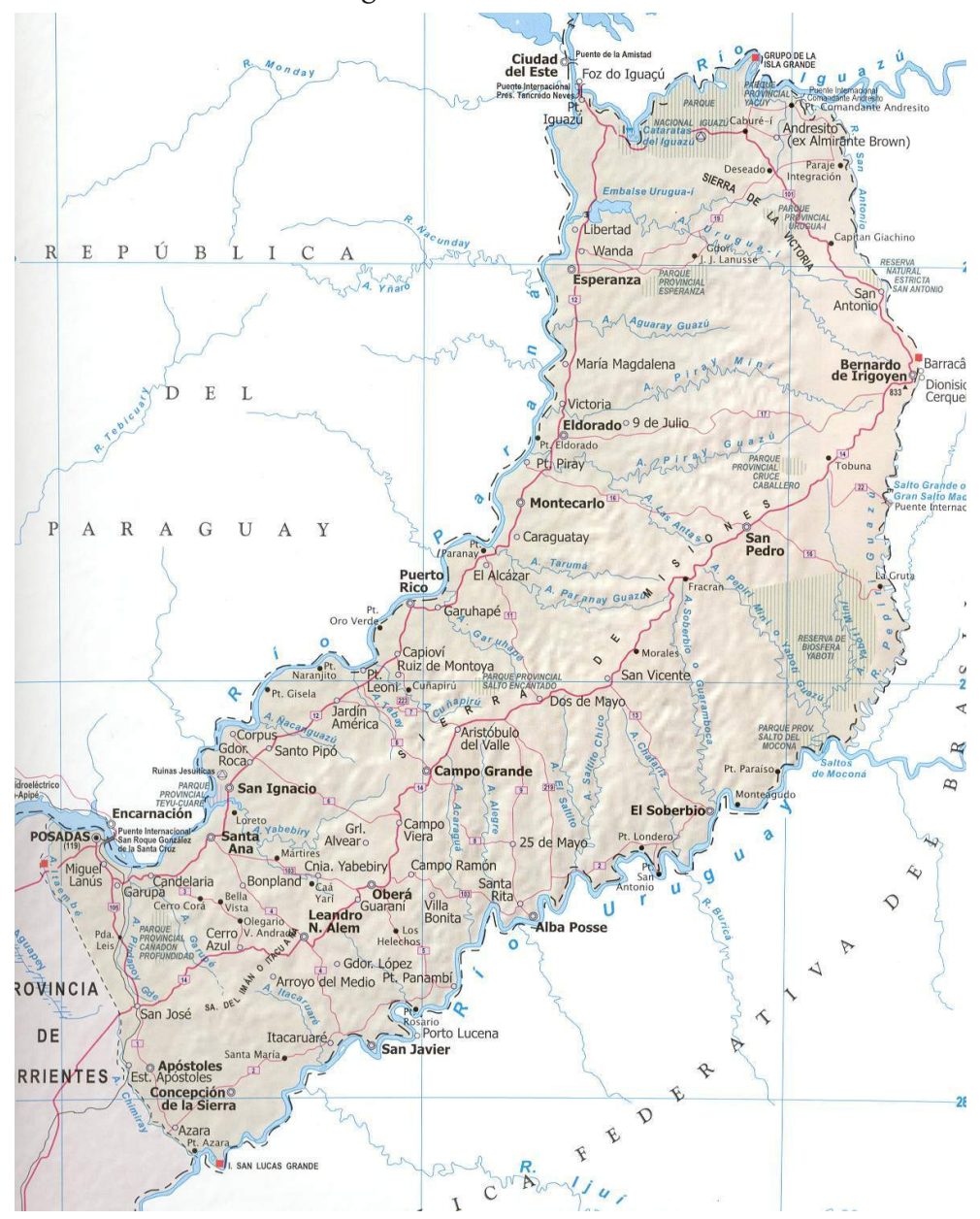

Fonte - Disponível em: http://www.zonu.com/argentina_maps/Misiones_Province_Map_ Argentina.htm Acesso em 12 de nov. 2015 
Segundo Mercanti, em um passado não tão distante, Misiones tinha uma vegetação exuberante, que gradativamente foi cedendo espaço aos cultivos, destacando-se: a erva-mate, o chá, o tungue, a cana de açúcar, o milho, a mandioca, a soja, e enormes extensões de plantio de árvores madeiráveis com grande valor econômico. ${ }^{12}$

De acordo com Mercanti,

A selva subtropical missioneira e o bosque natural ocupam dos 3.000 .000 hectares da superfície da província 1.250 .000 ha, que estão, em sua maior parte, degradadas ou convertidas em capoeira e 360.000 são áreas inacessíveis. O Parque Nacional del Iguazú e a Reserva Províncial de Pinheiros, próxima a San Pedro somam 70.000 ha. ${ }^{13}$

O Pinheiro Brasileiro ou "Pino Misionero" (Araucaria Angustifolia), é mencionado por Mercanti como uma:

[...] conífera nativa que ocupava grandes extensões do Nordeste (Misiones) e que atualmente teve a sua área de expansão tremendamente reduzida, se encontra nos Departamentos de General Belgrano e São Pedro, com continuidade mais densa no território brasileiro. ${ }^{14}$

$\mathrm{Na}$ citação do autor percebemos que o pinheiro, para os argentinos, também é considerado como originário da própria região, mesmo recebendo a denominação de pinheiro brasileiro como sinônimo do Pino Misionero.

\section{Viajantes: suas visões e argumentos}

No entender de Alfredo S. C. Bolsi, a segunda metade do século XIX se configurava em um momento pioneiro na história científica argentina. Faziam parte deste período as explorações e viagens científicas, organizadas por entidades governamentais e/ou científicas para percorrerem as regiões do país, permitindo com que houvesse um melhor reconhecimento das fronteiras, assim como da flora e fauna existentes. Ainda, de acordo com o referido autor, "as ciências naturais, filhas prediletas da época e com elas a incipiente antropologia atraíram uma ampla gama de intelectuais e estudiosos argentinos $[\ldots]^{15}$

\footnotetext{
${ }^{12}$ MERCANTI, Jose Alejandro. Economia forestal de Misiones. Posadas: Ediciones Montoya, 1983. p. 9

${ }^{13}$ Ibidem, p. 11.

${ }^{14}$ Ibidem.

${ }^{15}$ AMBROSETTI, Juan B. Dos estudios sobre Misiones: Viaje a las Misiones argentinas y brasileras por el Alto Uruguay. Rapida ojeada sobre el Territorio de Misiones. Estudio preliminar Alfredo S.V. Bolsi. Resistencia: Instituto de Investigaciones Geohistóricas, 1983, p.1
} 
As viagens para a Província de Misiones, que serão analisadas, ocorreram nas últimas décadas do século XIX, sendo que neste período as questões relacionadas com as Missões Jesuíticas, assim como as disputas de fronteiras já estavam, em grande parte, ultrapassadas, pelo menos politicamente. Segundo Bolsi, "o drama missioneiro já tinha acabado e o tempo e as novas perspectivas que se vislumbravam iam fechando as profundas feridas." 16 Infelizmente, o mesmo não pode ser dito em relação às questões ambientais, cujas feridas permaneciam e permanecem abertas.

Neste cenário, os viajantes ao chegarem na região encontravam "uma sociedade híbrida em Misiones, constituída por uma população composta essencialmente pelo elemento mestiço de europeu e indígena, além de tribos guaranis espalhadas pelo seu território."17

Os relatos do primeiro viajante, a serem discutidos, seguindo uma ordem cronológica das viagens, foi Rafael Hernández, nascido em 10 de setembro de 1840 na província de Buenos Aires e vindo a falecer em 21 de março de 1903. Obteve o título de agrimensor nacional pela Universidade de Buenos Aires, atuando na referida profissão além de ter sido político, militar e escritor. Foi nomeado em 20 de fevereiro de 1883, pelo Departamento Nacional de Agricultura para localizar e medir duas colônias, no departamento de Candelária e Santa Ana, no território de Misiones, e para tal se deslocou no mesmo ano, permanecendo por 4 meses executando o serviço. As aventuras da sua expedição foram relatadas em forma de "cartas" publicadas, a partir de julho de 1883, no periódico La Tribuna Nacional e, de acordo com Bruno Aranha, tinham a função de representar os interesses do Governo de Julio A. Roca, e com isto "construir a imagem de mudanças edificadas pelo governo" sendo que os relatos de viagem ajudavam a projetar os ideais de progresso e civilização" do Governo nacional. ${ }^{18}$

No ano de 1887, com o título de Cartas Misioneras - Reseña Histórica, Científica y Descriptiva de las Misiones Argentinas, foi publicada a obra completa de Rafael Hernández, trazendo uma carta de apresentação do presidente da Republica Julio A. Roca. ${ }^{19}$

Em uma das primeiras cartas, Hernández lamenta não poder enviar notícias com mais frequência e atribuiu o fato às suas tarefas assim como à

\footnotetext{
${ }^{16}$ Ibidem, p. 14.

${ }^{17}$ ARANHA, op. cit. p. 49.

${ }^{18}$ Ibidem, p. 54.

${ }_{19}$ HERNÁNDEZ, Rafael. Cartas Misioneras: Reseña Historica, Cientifica e Descriptiva de las Misiones Argentinas. Buenos Aires: Luz Del Alma, 1887.
} 
escassez de ferramentas para enfrentar os obstáculos encontrados. Para o agrimensor, as áreas visitadas se encontravam "em um terreno montanhoso, coberto de bosques seculares, que é necessário atravessar com o facão em mãos, entre espinheiros impenetráveis e barrancos que são às vezes grandes precipícios $[. . .]^{20}$

O autor no decorrer da escrita dá destaque a agricultura pois, e, no seu entender é ela que recebia a preferência dos colonos, pois fornecia abundantes resultados. E segundo o mesmo, os cultivos já existentes como: cana-de-açúcar, erva-mate, mandioca, arroz, milho, feijão, tabaco, café, algodão, amendoim, sorgo e anil, se constituem como essenciais para o futuro.

Em sua carta indicada como IX, Hernández relatou o seu contato e convívio com Carlos Bosetti, imigrante italiano, e que anos mais tarde também seria mencionado nas obras de Ambrosetti. Para Hernández, Bosetti era considerado um dos grandes ervateiros e conhecedores de Misiones, como pode ser observado no comentário:

Os homens do governo não têm ideia, me dizia, nem mesmo os proprietários das riquezas que se tem em madeiras preciosas ao Norte e Leste de Misiones. Os pinhais são inacabáveis, a sua altura alcança 45 a 50 metros e com circunferências enormes. ${ }^{21}$

Em relação às sensações que Hernández teve ao penetrar na floresta é interessante observar que, ao mesmo tempo em que enobrecia a paisagem, clamava para a importância e a necessidade da ação humana, para acordar a "majestade adormecida":

Nada pode explicar a não ser sentindo, o prazer que se apodera no animo de ir pouco a pouco e penetrar ao fundo destas matas de ramagens espessas de verdes, onde jamais chegou a luz do sol e nas quais hoje o clamor da vida humana, da civilização e do trabalho, arrancam pela primeira vez do seu imponente silencio, que como um sudário de morte as envolve na plenitude de sua existência. Parece com que se adentra o mistério de uma majestade adormecida. $^{22}$

Para o autor não restava dúvidas que a projeção de Misiones em nível nacional, só aconteceria através do progresso econômico e este só seria possível através da mão humana, representada pela imigração e a ação mais efetiva do Estado, pois após a descrição da exuberância da natureza ele co-

\footnotetext{
${ }^{20}$ Ibidem, p. 51-52.

${ }^{21}$ Ibidem, p. 87-88.

${ }^{22}$ Ibidem, p. 144-145.
} 
mentava:

Mas a riqueza dos produtos, os depósitos auríferos, os bosques intermináveis, as madeiras preciosas, as imensas artérias fluviais, os arroios impetuosos, a variedade e exuberância da vegetação, são tanto grandes espetáculos para alentar o coração de empresas esforçadas, como grandes empórios que as industrias do futuro irão frutificar em proveito da civilização. ${ }^{23}$

A obra de Rafael Hernández está dividida em duas partes, a mais extensa delas para o público em geral, ou seja, as cartas que já haviam sido publicadas no periódico La Tribuna, e a segunda com aspectos técnicos dirigidos ao Presidente da República e aos diretores do Departamento Nacional da Agricultura.

A primeira colônia escolhida e medida recebeu o nome de Colonia Candelária, no Departamento ${ }^{24}$ com o mesmo nome. Havia sido um antigo povoado das reduções jesuíticas. A sua localização geográfica tem como referencia principal o arroio de Garupá, que o limita a Oeste e também se constitui na divisa da Província de Corrientes com o Territorio Nacional de Misiones (Mapa 2) e assim "a Colonia é o primeiro ponto obrigatório a se tocar quando se entrar nele [...].”25

Hernández enumerou 17 aspectos com justificativas sobre a escolha do local para a instalação da colônia, onde ressaltamos alguns deles: terras públicas, que eram escassas em Misiones; uma base de população estabelecida; o clima benéfico, a fertilidade das terras demonstradas pelos produtos existentes; proximidade a centros mercantis e sociais, como Posadas e Encarnacion; facilidade de comunicação via fluvial e terrestre; um bom porto para escoamento dos produtos; abundância de madeiras, taquaras e pedras para construção; excelência e abundância de água; facilidade para estabelecer um sistema de regadio que em poucos anos transformaria o local em um grande centro industrial e agrícola; abundância de combustível, caça, pesca e elementos para a instalação dos primeiros povoadores; um terreno alto e arejado próprio para o povoado, não tão distante do porto nem tão próximo da costa que alcançasse as emanações insalubres do rio e seus banhados e, por último, a conveniente exposição e beleza da paisagem. ${ }^{26}$

\footnotetext{
${ }^{23}$ Ibidem, p. 146.

${ }^{24}$ Atualmente a Argentina é formada por 23 províncias, além de uma capital federal que é a cidade autônoma de Buenos Aires. As províncias se dividem em departamentos e estes estão divididos em municípios.

${ }^{25}$ Ibidem, p. 7.

${ }^{26}$ Ibidem, p. 7-8.
} 
Mapa 2 - Mapa da Região do Alto Paraná - Misiones



HASSEL, Hermann F. Deutscher Kalender for den Alto Parana 1938. Posadas: Druck F. O. Schenker y Cia., 1938. p. 197. Acervo: Acervo: Biblioteca Nacional da República Argentina.

Todos os itens acima mencionados, descritos e analisados minuciosamente pelo agrimensor, têm a paisagem como pano de fundo, e onde os recursos naturais se encontram à disposição dos humanos para serem utilizados.

De acordo com Hernández, a fauna, tanto em Candelária, quanto em Santa Ana, não era expressiva. Entretanto, o autor deixou evidente que nas demais áreas de Misiones era significativa a presença de animais como: tigre, leão, tamanduá, jaguatirica, cervo, aguará, anta, carpincho, tateto e cer- 
vo silvestre. Entre as aves destacavam-se pavões, papagaios, patos diversos e pássaros canoros. ${ }^{27}$

Em 1894, portanto, onze anos após a medição e estabelecimento da Colônia Candelária, a expedição de Ambrosetti, o nosso segundo viajante, passou pela vila e as suas impressões sobre a mesma são detalhadas em oito páginas. Juan Bautista Ambrosetti, nasceu em 22 de agosto de 1865 em Gualeguay, na província de Entre Rios e faleceu 28 de maio de 1917 em Buenos Aires. É reconhecido, atualmente, na academia nacional e internacional como um importante etnógrafo, folclorista e naturalista argentino.

O referido autor descreve como encontrou a nova colônia de Candelária, que começava a se povoar, já tinha várias casas de alvenaria, bem construídas, ainda distantes umas das outras, além de lamentar as dificuldades pelas quais os colonos tiveram que passar para obter a escritura da propriedade. Ainda, de acordo com Ambrosetti, Candelária tinha no período de sua visita, mais de mil habitantes, espalhados em chácaras e que se dedicavam principalmente à plantação de fumo. 0 autor menciona a necessidade de vias de comunicação para escoamento atual e futuro da produção, entre outros aspectos. ${ }^{28}$

A segunda colônia medida e fundada por Rafael Hernández foi Santa Ana, localizada no Alto rio Paraná, e, que assim como Candelária, também havia sido uma redução jesuítica, fato que poderia ser testemunhado pelas ruínas de pedras, laranjais e outros vestígios encontrados. Segundo o autor, não havia muito mais a acrescentar daquilo que foi descrito em relação à Candelária, pois eram muito parecidas. o diferencial, segundo o autor, seria a quantia de florestas e aguadas que eram em número bem maior, e, por conseguinte mais favorecidas para a agricultura. ${ }^{29}$

A colônia de Santa Ana, também foi descrita por Ambrosetti na passagem com a sua comitiva, e em suas observações mencionou que os habitantes da colônia nacional tinham passado por inúmeras dificuldades para alcançar o progresso desejado e, no seu entender pelas mesmas razões enfrentadas por Candelária. $\mathrm{E}$, segundo o autor, talvez sob o controle do governo Provincial a colônia poderia se desenvolver, e com a entrada de inúmeros imigrantes se transformaria no futuro em um importante centro populacional e de produção de Misiones. ${ }^{30}$

\footnotetext{
${ }^{27}$ Ibidem, p. 13.

${ }^{28}$ AMBROSETTI, Juan B. Tercer Viaje a Misiones. Buenos Aires: Editorial Albatroz, 2008. pp. 29-36.

${ }^{29}$ HERNÁNDEZ, op. cit., p. 16.

${ }^{30}$ AMBROSETTI, 2008, op. cit., p. 51.
} 
O segundo viajante, Juan Bautista Ambrosetti, introduzido anteriormente, também percorreu partes de Misiones e suas descrições sobre os recursos naturais fazem parte da nossa análise. A vida pública de Juan Bautista Ambrosetti assim como a acadêmica ${ }^{31}$ foi bastante ativa e acabou enriquecida através de suas viagens. Para o presente trabalho discutiremos aspectos das três viagens feitas para a província de Misiones, realizadas entre os anos de 1891, 1892 e 1894. Bolsi considera que os "seus relatos quase fotográficos da realidade que observou e descreveu, tem hoje, como se pode imaginar, um valor incalculável." ${ }^{32}$ No final do século XIX as atividades extrativistas estavam deixando evidentes os efeitos nocivos da intensa e descontrolada depredação, de modo que também apareciam os "primeiros sintomas de agonia.", o que também pode ser observado na Figura 1.

Os imigrantes do final do século XIX, com sua tradição agrária, facilitaram a transição para as atividades agropecuárias na região. Bolsi, em sua análise, considera como positiva a expansão da agricultura e a substituição cada vez maior da antiga e arriscada tarefa de localizar e explorar os ervais nativos da floresta ${ }^{33}$.

Segundo Bolsi, o período em que Ambrosetti esteve em Misiones pode ser considerado como um período de transição onde:

Um território que em consequência de dois povoamentos sucessivos e distintos está abandonando as antigas formas predatórias de exploração dos recursos e começa a sua vida agrícola, atividade esta que se converteu na base fundamental de economia missioneira. ${ }^{34}$ (tradução nossa)

A primeira viagem de Ambrosetti ${ }^{35}$ teve início em setembro de 1891 e se encerrou em fevereiro em 1892. Para a expedição se locomover, foram utilizados os mais variados meios de transporte, como vapores, canoas, trens, cavalos, mulas e carroças. Foi através da navegação pelo rio Uruguai que adentrou no Rio Grande do Sul, visitando as antigas reduções jesuíticas, assim como "grandes vazios" ao norte de Misiones entre outros.

\footnotetext{
${ }^{31}$ Ambrosetti publicou mais de cem artigos, sendo que 20 deles, entre os anos de 1883 a 1904, estão publicados no Boletin del Instituto Geografico Argentino.

${ }^{32}$ AMBROSETTI, 1983, op. cit., p. 11.

${ }^{33}$ Ibidem, p. 15.

${ }^{34}$ BOLSI, op. cit., p. 16.

${ }^{35}$ No período em que Ambrosetti visitava a região pela primeira vez, ainda parte da área estava em litígio com o Brasil (a parte compreendida entre o rio Iguaçu, os córregos Santo Antonio-Mirim e Peperi-Guaçu, o rio Santo Antonio e o Alto Uruguai).
} 
Figura 1- Pinhal em Misiones em processo de desmatamento.

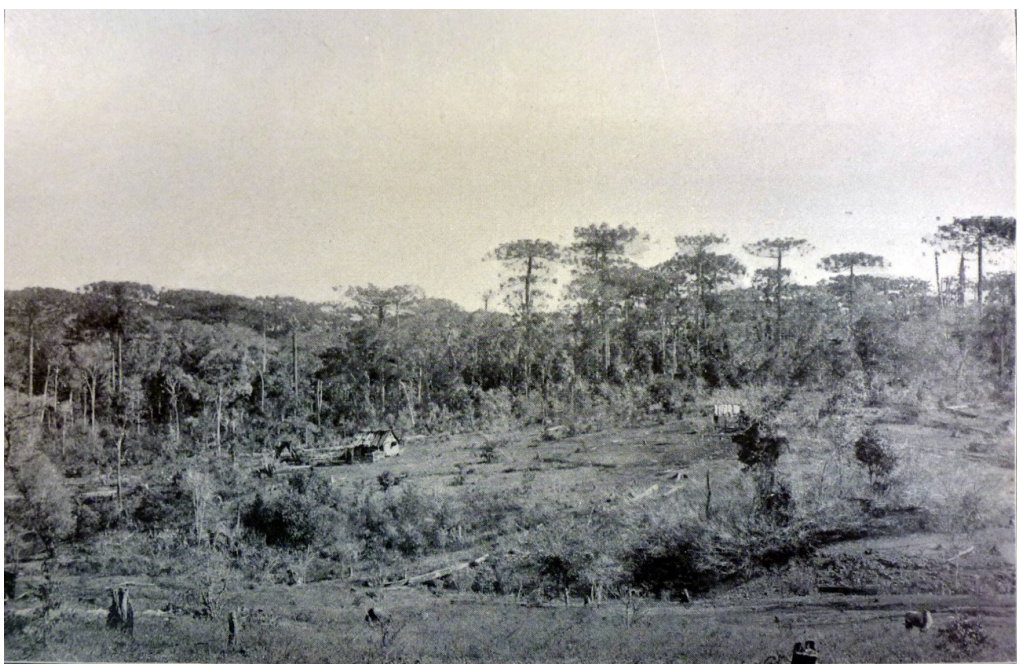

Fonte: BURMEISTER, Carlos. Memória sobre el território de Misiones. Buenos Aires: Imprenta, Litog. y Encuadernacion de J. Peuser, 1899. p. 91. Acervo: Biblioteca Nacional da República Argentina.

Parte da trajetória da viagem de Ambrosetti foi feita pelo Brasil na região do Alto Uruguai, e o viajante aproveitou para fazer comparações entre os dois territórios. Durante a sua travessia pelo rio Uruguai observou que grandes trechos do lado brasileiro estavam roçados e com plantações de cana-de-açúcar, milho e outros cultivos. Enquanto na mesma região, só que em território argentino, ela se "apresenta virgem, selvagem, com sua vegetação exuberante." ${ }^{36}$ As explicações para esta diferença entre as duas áreas podem ser encontradas no modelo de estabelecimento de colônias de imigrantes e descendentes no lado brasileiro, pois as florestas eram as mesmas, no passado, somente separadas pelo rio Uruguai. A busca de novas terras no Rio Grande do Sul gerou um processo migratório a partir das "colônias velhas" para a região do Alto Uruguai, nas três últimas décadas do século XIX, fazendo com que o desmatamento acontecesse rapidamente. ${ }^{37}$

\footnotetext{
${ }^{36}$ AMBROSETTI, 1983, op. cit., p. 106-107.

${ }^{37}$ Ver: NODARI, E. S. "As florestas no sul do Brasil: entre discursos de preservação e ações de devastação." In. FRANCO, J. L. de A.; DUTRA e SILVA, S.; et al (Orgs). História Ambiental: fronteiras, recursos naturais e conservação da natureza. Rio de Janeiro: Garamond, 2012. p. 241-260; NODARI, E.S. Etnicidades renegociadas: práticas socioculturais no oeste de Santa Catarina. Florianópolis: UFSC, 2009.
} 
As descrições, feitas por Ambrosetti, são cheias de detalhes, como os nomes dos rios, riachos, picadas abertas, assim como a relação das pessoas com as quais mantinha contato.

Um dos aspectos pitorescos narrados, e talvez muito pouco conhecido, pelo menos pelos historiadores, se refere a um tornado, mencionado como ciclone ${ }^{38}$. Segundo o autor:

Muito cedo seguimos a caminhada: atravessamos umas capoeiras antigas, o arroio Socorro, baixamos duas encostas e chegamos ao Lajeado Grande: a floresta mudou de aspecto: pouco depois de sair de Francrán, começamos a ver os terríveis efeitos de um ciclone. Toda a floresta estava no chão: as arvores arrancadas pela raiz, apresentavam a cada passo um paredão com suas raízes de 2 a 3 metros de altura e os buracos deixados por estas se abriam a cada instante no solo $[\text {... }]^{39}$

Recentemente, tornados têm atingido o Oeste de Santa Catarina, em áreas cujas coordenadas geográficas são idênticas ao do mencionado na Argentina.

Uma das primeiras vilas visitadas foi San Pedro de Monteagudo, localizada, segundo Ambrosetti, no meio de um "enorme pinhal rodeado de ervais." $\mathrm{Na}$ continuidade da viagem menciona que estava "caminhando entre os pinhais com uma ou outra mata de caraguatá e de cactos." ${ }^{40} \mathrm{E}$ ainda no mesmo trajeto se impressionou com a imensidão da floresta, pois árvores como: timbaúba, grápia, canafístula, cangaraná, sete capotes, angico se sucediam intermináveis. A imponência da araucária é destacada entre as demais árvores:

As caunas parecidas com a erva-mate, os grandes tarumás com a base de seu tronco recortada, as cerejas, [...] se alternavam, se juntavam, se intrincavam, lutando todos em uma tentativa desesperada de espaço em busca de ar e luz e sobre eles, erguendo-se majestoso o pinheiro com sua copa simétrica. ${ }^{41}$

A segunda viagem foi feita entre os meses de julho a dezembro de 1892, sob os auspícios do fundador e diretor do Museu de La Plata, Francisco P. Moreno, sendo denominada como Expedição Científica ao Nordeste. Além de Ambrosetti, a comitiva contou com a participação de Adolfo Methfessel, responsável pelos desenhos e pinturas da paisagem, e Emilio Beaufils,

\footnotetext{
${ }^{38}$ Ambrosetti se refere a um ciclone, todavia poderia ser um tornado devido a região em que se encontra a localidade.

${ }^{39}$ AMBROSETTI, 1983, op. cit., p. 125.

${ }^{40}$ Ibidem, p. 128.

${ }^{41}$ Ibidem.
} 
encarregado da parte zoológica. A obra, publicada no Boletín del Instituto Geográfico Argentino, se concentra em fazer uma descrição da viagem realizada pelos rios Alto Paraná e Iguaçu. Para Ambrosetti o itinerário da expedição fez com que conhecesse "toda a costa que banha o Alto Paraná, me adentrei nos grandes ervais paraguaios de Tacurú Pucú e assisti à elaboração deste precioso vegetal desde o seu corte da planta." ${ }^{42}$

Entre os meses de fevereiro a julho de 1894, sob o patrocínio do Instituto Geográfico Argentino, Ambrosetti e uma comitiva realizaram a terceira viagem à Misiones, tendo entre seus objetivos completar os dados existentes a respeito da região e "colecionar objetos para enriquecer as seções de etnografia e arqueologia do museu". ${ }^{43}$

Ambrosetti descreveu aspectos que considerou importantes para a região, sendo que o clima mereceu amplo destaque, sendo considerado admirável, onde o calor durante o dia seria compensado pelo frescor invariavelmente à noite; os imensos bosques que cobrem as altas serras "funcionando como desinfetantes enormes com seus perfumes ardentes, embalsamam o ar dando aos corpos energias vigorosas e uma saúde de ferro." ${ }^{44}$ Ainda menciona que o tipo de clima existente favoreceria a produção agrícola, com destaque para os seguintes cultivos: café, tabaco, cana-de-açúcar, algodão, anil, mandioca, milho, feijão, arroz e amendoim.

A floresta existente, de acordo com o referido viajante, seria importante economicamente, pois a abundância e a variedade das madeiras serviriam para diferentes usos, desde a lenha para queimar até a madeira mais rica para as obras mais delicadas. ${ }^{45}$ Mencionou ainda outros benefícios que a floresta oferecia tanto para os seres humanos assim como para a fauna, pois os bosques se encontravam repletos de frutas silvestres como, por exemplo: jabuticabas, gabirobas, cerejas, pinhões, entre outras tantas. ${ }^{46}$

Ambrosetti era um árduo defensor da ocupação da região por colonos, pois de acordo com o seu ponto de vista "não existe nenhuma outra região como Misiones para colonizar: ali tem todos os elementos à mão, só se necessita o trabalho humano para tirar da natureza mais do que o necessário a remuneração do suor derramado." ${ }^{77}$

\footnotetext{
${ }^{42}$ AMBROSETTI, Juan B. Segundo Viage a Misiones (Por el Alto Parana e Iguazú). Boletín del Instituto Geografico Argentino, tomo XV, 1894. p. 156.

${ }^{43}$ AMBROSETTI, 2008, op. cit., p. 24.

${ }^{44}$ Ibidem, p. 141.

${ }^{45}$ AMBROSETTI, 1983, op. cit., p. 141.

${ }^{46}$ Ibidem.

${ }^{47}$ Ibidem, p. 141-142.
} 
Ambrosetti concluiu a obra, mostrando a importância da colonização para Misiones e deixando claro que as alterações nas paisagens pela dominação humana seriam essenciais para o desenvolvimento econômico social e cultural:

Algum dia não tão distante, Misiones estará povoada como merece e quando os seus campos estiverem cultivados e o homem tenha transformado a natureza hoje inculta e ao cair da tarde se sente em um lugar tranquilo e satisfeito do seu trabalho diário, em meio de sua prole feliz $[. . .]^{48}$ (tradução nossa)

Observa-se que, na sua percepção, a natureza deveria estar a serviço dos seres humanos e, somente estes transformariam a província em uma região viável de forma social e econômica e assim podendo se igualar a outras regiões do país.

\section{Considerações finais}

No decorrer do texto foram discutidas as expedições de dois viajantes de nacionalidade argentina, ambos imbuídos da ideia de integrar o território de Misiones, de acordo com as metas previstas pelo governo argentino em "civilizar" regiões consideradas inóspitas e mesmo selvagens. Ambos estavam sendo financiados, mesmo que de forma indireta pelo poder público ou associações financiadas pelo mesmo.

Em uma comparação sobre como observavam a natureza, pode-se afirmar que na narrativa feita por Hernández a paisagem é mais romantizada, comparada com a de Ambrosetti. Todavia, ambos estão com um olhar utilitário ao que a natureza oferece ao homem para ser explorada economicamente.

Mesmo se demonstrando admirados com o que observavam, como por exemplo, Rafael Hernández, em vários momentos da sua obra, se diz surpreendido pela paisagem com suas variedades e matizes. Entretanto, em sua última carta, fica evidente que o autor não conseguiu se despir do seu olhar de homem de um grande centro como Buenos Aires, se comparado com as pequenas vilas/cidades de Misiones. $O$ autor se considerou o tempo em que esteve visitando a região como um estrangeiro, feliz em retornar "ao solo da Pátria", afinal de acordo com as suas palavras: "nos consideramos como estrangeiros nesta parte do seu território que ainda não tem os ares da vida culta e civilizada". ${ }^{49}$

\footnotetext{
${ }^{48}$ Ibidem, p. 142.

${ }^{49}$ HERNÁNDEZ, op. cit., p. 143.
} 
Este tipo de constatação vem como reforço à nossa ideia de que as fronteiras políticas, muitas vezes, são muito distintas daquelas as quais nós imaginamos. Rafael Hernández, se sentia um estrangeiro ao penetrar na "Selva Misioneira", afinal no seu entender era um mundo de barbárie, muito diferente daquele no qual ele estava acostumado a viver.

Enquanto que Ambrosetti, no encerramento da sua obra referente à terceira viagem, faz uma retrospectiva, afirmando que "em todas elas tive bons e maus momentos, talvez mais dos últimos, mas apesar de tudo, a impressão que esta terra maravilhosa deixou em mim é profunda." ${ }^{50}$ Todavia, o autor pretende se lembrar de aspectos da natureza, todavia, sem defender a necessidade de preservação da mesma.

Discutir territórios que apresentam as mesmas características e fazendo parte de um mesmo bioma, em dois países, se tornou um exercício bastante desafiador e continua inconcluso. As décadas analisadas, através dos relatos de dois viajantes argentinos, correspondem a um período em que as fronteiras políticas dos dois países estavam em disputa. Ambas as regiões ficavam distantes do Governo federal, seja no Brasil ou seja na Argentina e por muito tempo eram consideradas periféricas. As atenções se voltaram para as mesmas quando foi constatada a importância econômica que a natureza representava, com suas madeiras, com a extração da erva-mate e com a fertilidade do solo. Atualmente, podemos afirmar que os territórios de Misiones e parte do Rio Grande do Sul e Santa Catarina no Brasil, eram e continuam contínuos, não somente em comparação com a natureza, mas também com os problemas enfrentados para a preservação e sustentabilidade das regiões. Uma História Ambiental comparada sobre estes territórios atualmente, provavelmente mostraria que o modelo de ocupação adotado pelos dois países foi idêntico e, em grande parte responsável pelos problemas socioeconômicos e ambientais existentes.

Artigo enviado para publicação 08/10/2015

Artigo aprovado para publicação 13/11/2015

${ }^{50}$ AMBROSETTI, 2008, op.cit., p. 154. (tradução nossa) 